\title{
Multi-criteria planning of microgrids for rural electrification
}

\author{
Shabbir Saleh Bohra', Amjad Anvari-Moghaddam², Frede Blaabjerg², Behnam Mohammadi-Ivatloo ${ }^{3}$ \\ 'Department of Electrical Engineering, Sarvajanik College of Engineering \& Technology, Surat 395001, India. \\ 2Department of Energy Technology, Aalborg University, Aalborg 9220, Denmark. \\ ${ }^{3}$ Faculty of Electrical and Computer Engineering, University of Tabriz, Tabriz 5166616471, Iran.
}

Correspondence to: Prof. Amjad Anvari-Moghaddam, Department of Energy Technology, Aalborg University, Pontoppidanstræde 101, Aalborg 9220, Denmark. E-mail: aam@et.aau.dk

How to cite this article: Bohra SS, Anvari-Moghaddam A, Blaabjerg F, Mohammadi-Ivatloo B. Multi-criteria planning of microgrids for rural electrification. J Smart Environ Green Comput 2021;1:120-34. http://dx.doi.org/10.20517/jsegc.2021.06

\begin{abstract}
Received: 8 Apr 2021 First Decision: 6 May 2021 Revised: 25 May 2021 Accepted: 4 Jun 2021 First online: 15 Jun 2021
Academic Editors: Zeshui Xu, Witold Pedrycz Copy Editor: Yue-Yue Zhang Production Editor: Yue-Yue Zhang
\end{abstract}

\begin{abstract}
Aim: The objective of this study is to facilitate decision makers' selection of groups of components for isolated microgrid which should not only be economically attractive and efficient but also acceptable from various aspects. The microgrid is designed to serve a rural remote region of Tanzania with an approximate energy demand of $1000 \mathrm{kWh} /$ day.
\end{abstract}

Methods: A comprehensive comparison has been presented using (Hybrid Optimization Model for Electric Renewable) HOMER Pro software and fuzzy analytic hierarchy process (AHP)-based multi-criteria decisionmaking (MCDM) (fuzzy-AHP-MCDM) technique for planning of isolated microgrid systems which is formed by using a group of sources, like photo-voltaic (PV) generator, wind-turbine, micro-hydro, bio-gas based generation and battery storage system. In this study, ten various alternatives comprising a blend of the aforementioned sources have been considered. A group of households having an approximate load demand of $1000 \mathrm{kWh} /$ day located near Arusha in Tanzania has been selected for this study.

Results: A levelized cost of energy of $0.0694 \$ / \mathrm{kWh}$ has been found for the optimized case using HOMER Pro comprising all five aforesaid components.

Conclusion: The fuzzy-AHP-MCDM technique also exhibits highest priority for a similar combination when only the economic criteria are considered and all other criteria are being suppressed significantly. On the other side, a different group consisting only PV and wind-based generation is found prioritized when all criteria are taken 
into account with different weights, either based on experts' score or equal importance. Moreover, a sensitivity analysis has also been conducted to observe the impact of alternative selections.

Keywords: Microgrid, fuzzy-set, analytic hierarchy process, multi-criteria decision-making, energy planning

\section{INTRODUCTION}

The availability of low-priced electricity has completely transformed the modern world. And this has been achieved along with the use of petroleum products to form the energy backbone of modern life. According to the World Bank's World Development Indicators, about $85 \%$ of the world's households now have access to electricity, and the rest $15 \%$ belong to the world's absolutely poorest households ${ }^{[1]}$. Access to high grade electrical energy should be an absolute priority. Modern energy is now an essential requirement and none of the Sustainable Development Goals will be accomplished if this aspect is not complied with. SubSaharan Africa (SSA) has the lowest energy access rates in the world ${ }^{[2]}$. The electricity reaches only about half of its people, while clean cooking only to one-third; and roughly 600 million people lack electricity ${ }^{[3,4]}$. Thirteen countries in SSA have less than $25 \%$ access, compared to only one in developing Asia ${ }^{[5]}$.

A few years ago, only economical parameters were of prime importance for power system planners and operators. But now decision makers have realized that the planning should require not only financial aspects but also other facets of the project as far as facilitating electricity to underprivileged households is concerned ${ }^{[6]}$. This includes nearby resources of fuel and at reasonable price, local skills required to keep running the installed system, use of renewable energy sources to meet carbon emission norms, autonomy, self-supply, distance from load-center, acceptable noise level, and so on ${ }^{[7]}$.

An attempt was made to review quantitative and qualitative electricity planning and related implementation aspects by considering 49 SSA countries including four regional power pools and the sub-continent as a whole ${ }^{[8]}$. The formalized multi-criteria decision making (MCDM) tools have been employed in analysis. A microgrid is defined as a smaller power system employing one or more conventional and/or renewable distributed energy sources based generating units. This may be grid supportive or independently operating to feed for remote areas or villages where installation of transmission lines is economically not justifiable. Moreover, microgrid planning is a complex problem which involves technical, economic, social, and environmental considerations. Conventionally, the design and planning of microgrid targets best utilization of energy sources, minimum overall cost, better ancillary services, and resiliency and reliability. In order to plan a microgrid for a given location, approximate load demand should be known beforehand. Such assessment has been done for Tanzania based on interview and measurement, though it does not reflect the true load demand due to the lack of instruments and methodology adopted ${ }^{[9]}$. One of the IET's reports entitled "Power Network Joint Vision" elaborates on significant changes required in view of current practice in the assessment, planning and development of the power network facilities for future system operation. The report also discussed key hurdles, their solutions, planning techniques ${ }^{[10]}$. Similar, study was conducted in a scenario of power system planning under a high-penetration of solar $\mathrm{PV}^{[11]}$. The microgrid being emerging technology in the field of power system, the various technical aspects, key drivers and challenges are investigated ${ }^{[12]}$. The optimal output planning for each individual unit of microgrid comprising wind power, solar PV, gas turbines, and energy storage has been modeled using optimization algorithm with an objective of significant reduction in system operation cost by Wang et al ${ }^{[13]}$. A microgrid planning model ensuring adequate supply to critical loads under the uncertain condition is discussed in Wu et al. ${ }^{[14]}$ with minimizing the total cost during the whole project life, construction cost, and operation cost for the distributed energy resources. The overview of microgrid and its associated challenges, like planning, operation, and control, as well as protection aspects are briefly discussed in $^{[15]}$. It also helps planners and 
decision makers involved in setting up microgrids for rural households/villages becoming electrified. The concept of optimal design, planning, techno-economic analysis, sizing, and operation of a hybrid renewable energy-based grid-connected microgrid is explained in Hafez et al. ${ }^{[16]}$ with an objective to minimize the lifecycle cost. A comparison and evaluation are done mainly for economics, operational performance, and environmental emissions by using the HOMER software. An extensive survey of mathematical methods applied to microgrid planning based on economic feasibility from a capacity sizing standpoint has been conducted in two prior studies ${ }^{[17,18]}$ and can be useful for microgrid planners. MCDM is a methodology of operational research discipline to evaluate projects involving multiple and mutually conflicting features. Numbers of MCDM techniques are advocated suitable for providing optimal solutions to a various class of energy management and planning problems ${ }^{[19-21]}$. An analytic hierarchy process (AHP)-entropy method has been introduced for microgrid planning considering economy, reliability, basic structure of planning and environmental protection by He et al. ${ }^{[22]}$.

The applications of HOMER software in optimal planning of hybrid renewable energy sources have been surveyed by Bahramara et al. ${ }^{[23]}$ for wide range of electrical load and stand-alone and grid-connected mode as well. On the similar line of work, the mix of diesel and renewable energy are found in ${ }^{[16]}$ to have minimum net present value and less carbon footprint while pure renewable exhibits almost zero carbon emission but higher net present value for grid-connected microgrid analysis. The technical and economic analyses of hybrid renewable energy systems are considered to be essential ones for the efficient utilization of renewable energy resources for microgrid applications ${ }^{[24]}$. The optimum planning of renewable energy system comprising hybrid PV-Wind-BESS, which has been conducted for a small village in India having peak demand of approximately $27 \mathrm{~kW}$, has been investigated by Fulzele and Dutt ${ }^{[25]}$. Various important aspects addressing the challenges for rural microgrid design with an objective of optimal investment and planning using different techniques and tool are discussed by Heleno et at. ${ }^{[26]}$. Framework for microgrid has been proposed using multidisciplinary design optimization under uncertainty approach ${ }^{[27]}$. JiménezEstévez et al. ${ }^{[28]}$ also incorporated life-cycle-assessment module, so that the configuration can take care of economic and environmental impacts of the power system. The planning and design of isolated microgrids is discussed by Vafaei et al. ${ }^{[29]}$ focusing on their technical and investment costs. In the same work, they have employed traditional optimization technique for selecting sources and power generation technologies and storage devices to ensure minimal operating cost for microgrid. Logenthiran et al ${ }^{[30]}$ has explained differences between classical integer minimization problem and evolutionary strategy technique for sizing power equipment for isolated microgrid with an objective of minimizing capital, operational, and maintenance cost of energy sources. The applications of heuristic optimization techniques such as Genetic Algorithm, Particles Swarm Optimization, Simulated Annealing, Ant Colony (AC), and Artificial Immune Systems for renewable energy systems sizing have been discussed by Erdinc ${ }^{[31]}$. Chen et al. ${ }^{[32]}$ proposed a method based on the cost-benefit analysis for optimal sizing of an energy storage system in a microgrid. A designing of stand-alone microgrid to achieve optimum cost and sizing of storage for the Island of Singapore, and selection and capacity sizing of generators for a rural microgrid have been explained by Fan et al ${ }^{[33]}$ and Kumaravel et al. ${ }^{[34]}$, respectively and by other researchers as well.

However, though economic factors are greatly influential in deciding the type and size of sources of microgrid, their significance in terms of types and capacity as well may change if other non-tangible factors are given appropriate priority and this fact is being highlighted in this paper. Moreover, the Cost of Energy $(\mathrm{CoE})$ is one of the most sensitive and governing factors to decide the acceptance of a project by local consumers which has been looked at in this study. The aim of this study is to facilitate decision makers to achieve economic benefits along with other factors to be satisfied for planning of an isolated microgrid system catering a group of households, but it can be equally applicable to any size of the systems. The remaining of the paper is organized as follows. In section 2, the selected sample reference system is described. Section 3 explains the methodology adopted for analysis. The results are discussed in section 4 . Finally, section 5 concludes the paper. 


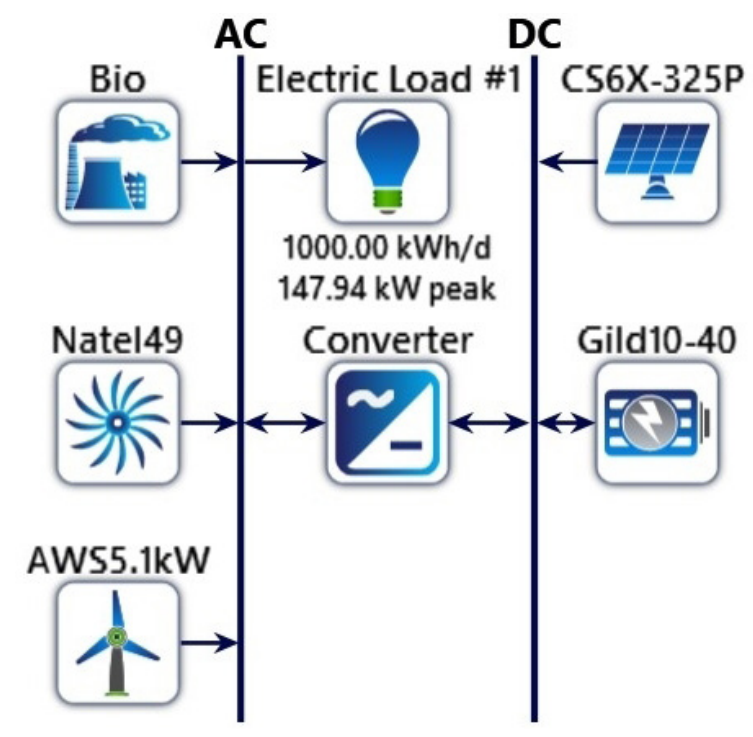

Figure 1. The microgrid power system model for Arusha, Tanzania developed in HOMER Pro ${ }^{[39]}$.

\section{SYSTEM DESCRIPTION}

The system under study is located in Tanzania and the objective is to make an electrification plan leveraging the multifold benefits of microgrids. Tanzania is the sixth-most populous country in SSA; it connects six land-locked countries to the Indian Ocean, and with the discovery of natural gas reserves, it opens opportunities for investment. Tanzania has abundant and world-class wind and solar resources ${ }^{[35]}$. But it is a low-income country, with a population of about 59.6 million in 2020 . About $66 \%$ of the population lives in rural areas. Tanzania has outlined its medium-term objective of becoming a middle-income country by 2025 , and the country also participates in seven regional projects with a total commitment value of $\$ 550.8$ million. The identified sectors in the national projects include: transport (22\%), urban development (20.5\%), energy $(13.5 \%)$, education $(10 \%)$, and governance $(10 \%)^{[36]}$. Arusha is a city in East Tanzania, located at the base of volcanic Mt. Meru. It is a gateway to safari destinations and to Africa's highest peak, Mt. Kilimanjaro, and to the west lie Serengeti National Park, which is home to wildlife.

Tanzania has immense solar and wind power potential, a global horizontal irradiation of $4-7 \mathrm{kWh} / \mathrm{m}^{2}$ per day, and average wind speed of $8.5-10 \mathrm{~m} / \mathrm{s}$. Moreover, biomass is a renewable energy source developed from living or recently living plant and animal materials. Methane rich bio-gas is produced when the biomass is anaerobically degraded by micro-organisms using anaerobic digestion ${ }^{[37]}$. According to a report by Prof. Siza Tumbo, the director general of the Arusha-based Centre for Agricultural Mechanisation and Rural Technology (Camartec) and implementing the Tanzania Domestic Biogas Programme, Tanzania has the third largest livestock population on the African continent and hence has enormous potential for biogas plants $^{[38]}$.

To model the examined system, that is, configuring the microgrid and its components, carrying out simulations and determining different energy planning scenarios considering different constraints, the HOMER Pro ${ }^{[39]}$ software is used. The microgrid is comprised of electric load, PV system, group of windturbines, bio-gas generator set (genset), micro-hydro power plant, battery energy storage system (BESS), and associated AC-DC converter as shown in Figure 1. The principal characteristics of the microgrid system are: 25 years project lifetime, 3\% expected inflation rate, and 5\% nominal discount rate. The various components for simulation study of the project including the number of units and capacity of each unit considered are shown in Table 1. 
Table 1. System architecture for studied microgrid model

\begin{tabular}{lll}
\hline Component type & \multicolumn{1}{c}{ Component name } & Capacity kW $\times$ units \\
\hline Generator & Generic Biogas Genset & $40 \times 1$ \\
PV system & Canadian Solar MaxPower CS6X-325P ${ }^{[40]}$ & $30 \times 1$ \\
Storage system & Gildemeister 10 kW-40 kWh CELLCUBE ${ }^{\circledR}$ FB 10-40 & $5 \times 5$ \\
Wind turbine & AWSHC 5.1kW Wind Turbine ${ }^{[42]}$ & $4 \times 4$ \\
Hydroelectric & Natel FreeJet FJ-7A 49kW & $49 \times 1$ \\
\hline
\end{tabular}

Many combinations could be possible depending on different energy sources and their units. In order to limit these combinations, the system has been simulated into HOMER Pro to identify a group of energy sources that offer the most economic performance. Therefore, out of several combinations of sources integrated into HOMER Pro forming microgrid, the one which has least CoE has been considered as a reference or base system for subsequent analysis. Thus, it infers that this system analysis takes mainly economic constraints into account. The respective economic parameters are now supplied to fuzzy-AHPbased MCDM method. Moreover, these base values are also used for sensitivity analysis to explore the impact of tangible parameters, like CoE and net present cost (NPC). For such projects, the lowest value of $\mathrm{CoE}$ acts as one of the most sensitive and deciding parameters for acceptance by households.

\section{METHODOLOGY}

The projects aiming improving living standards for underprivileged and/or people living in underdeveloped Asian or African countries should have holistic approach fulfilling multiple needs. And it is mainly measured by quantifiable things, such as income, employment opportunities, cost of goods and services, and poverty. The accessibility of electrical energy should meet certain bare minimum demand, leaving the environment minimally polluted and preserving the natural beauty of the surrounding and habitat. Furthermore, the project should also facilitate generating of employment opportunities for locals' and hence impacts the living standards directly or indirectly. The objective of this study is to highlight the fact that economic indicators alone are not sufficient to decide the overall success of such project. Other aspects also, which seem to be less influential at a first glance, should be given due importance. A techno-economic analysis for an approximate demand of $175 \mathrm{kWh}$ /day by a group of houses located remotely catered by photovoltaic mini-grid systems has been projected by Daniel for Nigeria ${ }^{[4]}$. A composite nature of a load profile for a typical village-having a population of around 2500-3000 people and therefore demanding an approximate electrical demand of $1000 \mathrm{kWh} /$ day has been considered. The composite load may include lights, fans, other typical domestic loads per household, water purifying system, mini/small industrial loads like cutting, sewing, and grinding machines, and a health care and school premise and its associated load ${ }^{[9]}$. In order to define a reference system and capacity of components, the HOMER Pro software has been widely used by researchers and planners in most analysis. The information of various sizes of sources with their associated parameters, such as its prevailing capital cost per $\mathrm{kW}$, operation and maintenance cost, lifetime, replacement cost, fuel cost (bio-gas), available potential at chosen location for solar irradiation (PV farm) and wind velocity (wind turbine) and details of power and energy BESS are supplied.

The daily irradiation of Arusha, Tanzania is estimated to be $6.17 \mathrm{kWh} / \mathrm{m}^{2}$ by the National Renewable Energy Lab database ${ }^{[45]}$ and this was utilized in simulation. The annual average wind velocity for the selected location is $5.35 \mathrm{~m} / \mathrm{s}$ from NASA Surface meteorology and Solar Energy database measured at $50 \mathrm{~m}$ above the surface of the earth ${ }^{[46]}$. Furthermore, it is estimated that under ideal conditions, $10 \mathrm{~kg}$ of biomass can produce 3 sq.mt of biogas. A set of simulations have been run to decide the most optimized system architecture based on $\mathrm{CoE}$ offered. In a later part of analysis, a comprehensive list of criteria has been gathered ${ }^{[47,48]}$ as depicted in Figure 2. Mainly five criteria such as economic, operational, structural, technical, and others as well as associated sub-criteria have been identified. The "others" criteria include environmental, appearance, inclination of stakeholders, emission level, and more. The impact of weights 


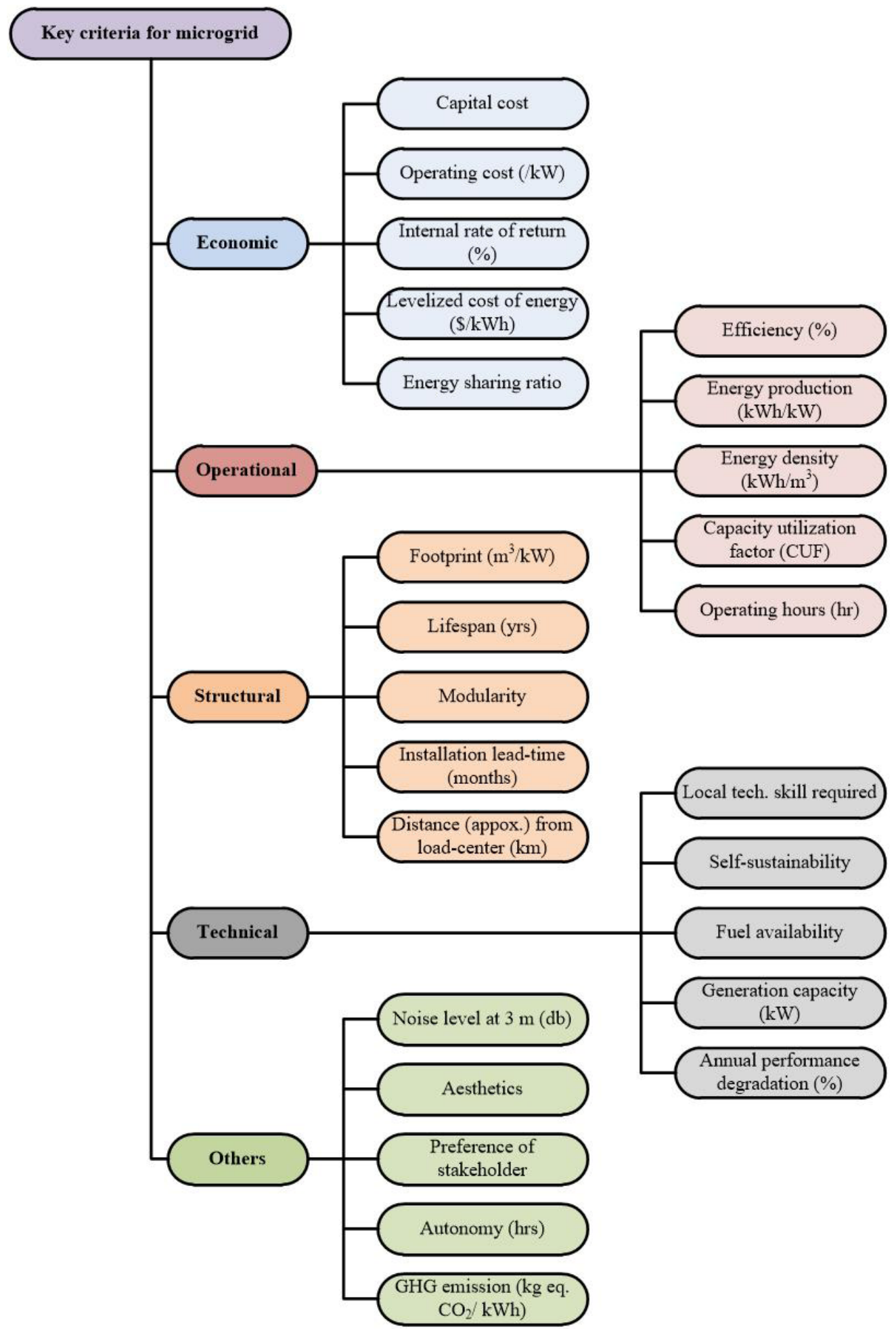

Figure 2. Categorized list of criteria for planning of microgrid.

has been analyzed in three ways: firstly, only economic parameters are given more than $70 \%$ importance and leaving all other with equal weights; secondly, all primary criteria are assigned equal weights of $20 \%$; and thirdly, expert opinions for the primary criteria are taken into account. 
The opinion of experts for set of primary criteria has been collected in the form of scores based on comparison of each other. In order to simplify the process of creating pair-wise comparison matrix with minimal influence of fuzziness involved in assigning score to criteria by experts, a method devised ${ }^{[49]}$ has been incorporated.

A group consisting of 15 members was asked to score five primary criteria such as economical, structure, technical, operation, and others; equal weights by assigning scores to each based on a numerical scale of 0-10 are done. These members are representing experts/stakeholders in respective groups and holding key positions for various vital project planning matters, like financing, designing, operating and maintenance, environment protector and social welfare workers, and end-users of electricity.

The collected opinions are real numbers and not the fuzzy sets. In this method a fuzzy number is constructed from a set of scores assigned by experts. The weight determination technique is utilized to take the distribution of the scores into account when estimating the mode and spreads of a fuzzy number. It is assumed that the criterion has been scored using a scale from 0 to 9 . Let $s_{1}, s_{2} \ldots, s_{n}$ represent the scores assigned to by various experts to same criterion. Due to preconception and expertise in particular areas, different experts are likely to score differently for the same criterion. Here, the approach developed by Cheng ${ }^{[49]}$ has been adopted to identify the membership function of a fuzzy number depending on $s_{1}, s_{2} \ldots, s_{n}$.

In the estimation process, experts' scores closer to the center are considered to have more importance. The estimation of this center is a weightage average of the $s_{i}$. The distance between each $s_{i}$ is computed to find relative distance matrix defined as follows:

$$
D=\left[d_{i j}\right]_{n \times n}
$$

where, $d_{i j}=\left|s_{i}-s_{j}\right|$, which implies that $d_{i j} \neq 0$ and $d_{i j}=d_{j i}$. The average of relative distance $\overline{\boldsymbol{d}}_{\boldsymbol{i}}$, for each $s_{i}$ is given by

$$
\bar{d}_{i}=\sum_{j=1}^{n} d_{i j} /(n-1)
$$

The smaller value indicates the proximity of $s_{i}$ to the center of all the scores. This average distance is used to measure the proximity of $s_{i}$ to the center of all the scores. The smaller the value of $d_{i}$, the closer the proximity of $s_{i}$ to the center and the greater its assigned weight while estimating the mode of the fuzzy number. To determine the degree of importance of each $s_{i}$ in this estimation method, pair-wise comparisons between $s_{i}$ are done based on their average distances. A pair-wise comparison matrix is given as below:

$$
\boldsymbol{P}=\left[\boldsymbol{p}_{i j}\right]_{\boldsymbol{n} \times \boldsymbol{n}} \text { and } \boldsymbol{p}_{i j}=\frac{\overline{\boldsymbol{d}}_{\boldsymbol{j}}}{\overline{\boldsymbol{d}}_{\boldsymbol{i}}}
$$

where, $p_{i j}$ is the relative importance of $s_{i}$ compared to $s_{j}$, which implies that $p_{i j}=1$ and $p_{j i}=1 / p_{i j}$, since, $P$ is derived from comparison distance, and it is absolutely consistent

Let $w_{i}$, the real weight of $s_{i}$, and $0 \leq \mathbf{w}_{\mathrm{i}} \leq 1$.

$$
p_{i j}=\frac{w_{i}}{w_{j}}, \forall i, j
$$

$$
P w=n w
$$

which implies that $n$ is an Eigen value of $P$ and $w$ is the corresponding Eigen vector

$$
\sum_{i=1}^{n} w_{i}=1 \text { and } w_{j}=1 / \sum_{i=1}^{n} p_{i j}, j=1, \ldots, n
$$

The importance degree $w_{i}$ serves as the weight to be associated with $s_{i}$ when estimating the mode of the fuzzy number. 
After getting a pair-wise comparison matrix of primary criteria, this information is fed into a computing device wherein pair-wise comparison for sub-criteria of each primary criterion is done based on quantitative values either obtained from HOMER Pro or from the methodology described by Bohra et al. ${ }^{[48]}$. The detailed specifications from manufacturer of the components have been used to achieve realistic results. The normalized pair-wise matrix $A_{\text {norm }}$ is obtainę using the following:

$$
\overline{a_{i j}}=a_{i j} / \sum_{i=1}^{m} a_{i j}
$$

where, $a_{i j}$ represents the importance of the $i^{\text {th }}$ criterion relative to the $j^{\text {th }}$ one and $m$ indicates number of evaluated criteria/sub-criteria to be compared. Then after, criteria weight vector $w$, which is $k$-dimensional column vector is computed taking mean of each row of $A_{\text {norm }}$ as per Equation (8),

$$
w_{i}=\left(\sum_{i=1}^{k} \overline{a_{i j}}\right) / k
$$

Let the $j^{\text {th }}$ entry of the $i^{\text {th }}$ criterion is being compared with the $l^{\text {th }}$ of the same criterion and assuming values for the same criterion lie in the interval of $\left[I_{j, \max }, I_{j, m i n}\right]$. The relative importance between criteria is ranked between 1-9; the scale was suggested by Saaty ${ }^{\left[{ }^{\prime m a x}\right]}$.

In AHP, the consistency of matrices can be measured by consistency index $(C I)^{[51]}$ as given in following:

$$
C I=\frac{\lambda_{\max }-m}{m-1}
$$

where, $\lambda_{\max }$ is the sum of product of associated weight and sum of respective column of pair-wise comparison. The competency of $C I$ can be validated by determining randomized (consistency) index (RI), the average $C I$ for randomly filled matrices. The consistency ratio $(C R)$ and $R I$ can be calculated as below:

$$
\begin{gathered}
C R=\frac{C I}{R I} \\
R I=\frac{\bar{\lambda}_{\text {max }}-m}{m-1}
\end{gathered}
$$

where, $\lambda_{\max }$ represents maximum Eigen value.

Based on the various systems installed across the world, ten alternatives have been chosen to form a group of sources as shown in Table 2 .

The CoE and NPC for microgrid system are obtained from following:

$$
\begin{gathered}
C o E=\frac{\text { Life time cost }}{k W h \text { in given life time }} \\
N P C=\sum_{t=0}^{n} \frac{\text { Net cash flow }}{(1+\text { Discount rate })^{t}}
\end{gathered}
$$

where, $t$ is time of cash flow and $n$ is total number of periods.

\section{DISCUSSION}

Since the microgrid is planned for remote and rural applications, it needs to be independent and not be interconnected with any utility grid system. In such scenario, the system CoE solely depends on various costs involved in setting up the system and its components. The base case system details are shown in Table 3. The dispatch control strategy adopted for simulation is load-following, meaning the operating generator produces only enough power to meet the primary load ${ }^{[39]}$. Moreover, no conventional fossil fuel is being used, while the renewable fraction for system is absolutely $100 \%$. From HOMER simulation results, the 
Table 2. Different alternatives considered in the optimization of microgrid

\begin{tabular}{lll}
\hline Sr. No. & Alternative & \multicolumn{1}{c}{ Combination } \\
\hline 1 & A1 & PV' + Wind \\
2 & A2 & PV + Hydro \\
3 & A3 & PV + Bio \\
4 & A4 & PV + Wind + Hydro \\
5 & A5 & PV + Wind + BESS \\
6 & A6 & PV + Hydro + BESS \\
7 & A7 & PV + Bio + BESS \\
8 & A8 & PV + Wind + Hydro + BESS \\
9 & A9 & PV + Wind + Bio + BESS \\
10 & A10 & PV + Wind + Hydro + Bio + BESS \\
\hline
\end{tabular}

${ }^{1}$ Solar PV system; ${ }^{2}$ wind-turbine; ${ }^{3}$ micro hydropower plant; ${ }^{4}$ bio-gas based gen-set; ${ }^{5}$ battery-energy-storage-system.

Table 3. Base case results obtained from HOMER Pro using alternative A10

\begin{tabular}{|c|c|c|}
\hline \multirow[t]{5}{*}{ Cost } & Dispatch control & Load-following \\
\hline & $\operatorname{COE}(\$)$ & 0.0694 \\
\hline & $\mathrm{NPC}(\$)$ & 327,231 \\
\hline & Operating cost ( $\$ /$ year) & 5002 \\
\hline & Initial capital $(\$)$ & 262,563 \\
\hline \multirow[t]{2}{*}{ System } & Renewable fraction (\%) & 100 \\
\hline & Total fuel (L/year) & 19.4 \\
\hline \multirow[t]{7}{*}{ Bio-gas based generation system (Bio) } & Bio lifetime (hours) & 17,500 \\
\hline & Biomass price $(\$ /$ tonne $)$ & 5 \\
\hline & Hours & 290 \\
\hline & Production (kWh) & 6206 \\
\hline & Fuel $(\mathrm{kg})$ & 19.4 \\
\hline & O\&M cost $(\$ /$ year $)$ & 77.3 \\
\hline & Fuel cost ( $\$ /$ year) & 96.9 \\
\hline \multirow[t]{2}{*}{ PV system (CS6X-325P) } & Capital cost $(\$)$ & 30,000 \\
\hline & Production (kWh/year) & 59,652 \\
\hline \multirow[t]{3}{*}{ Wind machine (AWS5.1kW) } & Capital cost $(\$)$ & 30,000 \\
\hline & Production (kWh/year) & 27,503 \\
\hline & O\&M cost $(\$ /$ year $)$ & 700 \\
\hline \multirow[t]{4}{*}{ BESS system (Gild10-40) } & Autonomy $(h)$ & 3.84 \\
\hline & Annual throughput (kWh/year) & 42,972 \\
\hline & Nominal capacity (kWh) & 200 \\
\hline & Usable nominal capacity (kWh) & 160 \\
\hline \multirow[t]{4}{*}{ Micro Hydro (Natel49) } & Natel49 capital cost $(\$)$ & 150,000 \\
\hline & Natel 49 available head $(\mathrm{m})$ & 7 \\
\hline & Natel49 flow rate $(\mathrm{L} / \mathrm{s})$ & 1200 \\
\hline & Mean output (kW) & 41.7 \\
\hline \multirow[t]{6}{*}{ Financial parameters } & Present worth $(\$)$ & 4974 \\
\hline & Annual worth $(\$ /$ year $)$ & 385 \\
\hline & Return on investment (\%) & 76.6 \\
\hline & Internal rate of return (\%) & 61.1 \\
\hline & Simple payback period (SPP) (year) & 1.63 \\
\hline & Discounted SPP (year) & 1.77 \\
\hline
\end{tabular}

COE: Cost of energy; NPC: net present cost; O\&M: operation and maintenace.

optimal alternative is found to be A10. The other system relevant parameters are also depicted in Table 3. The NPC is computed as $\$ 327,231$ and an initial investment cost of $\$ 262,563$ for alternative A10 as shown in Table 2. The other key financial indicators like return of investment (ROI), internal rate of return and simple payback period are $76.6 \%, 61.1 \%$ and around 1 year 8 months, respectively. 


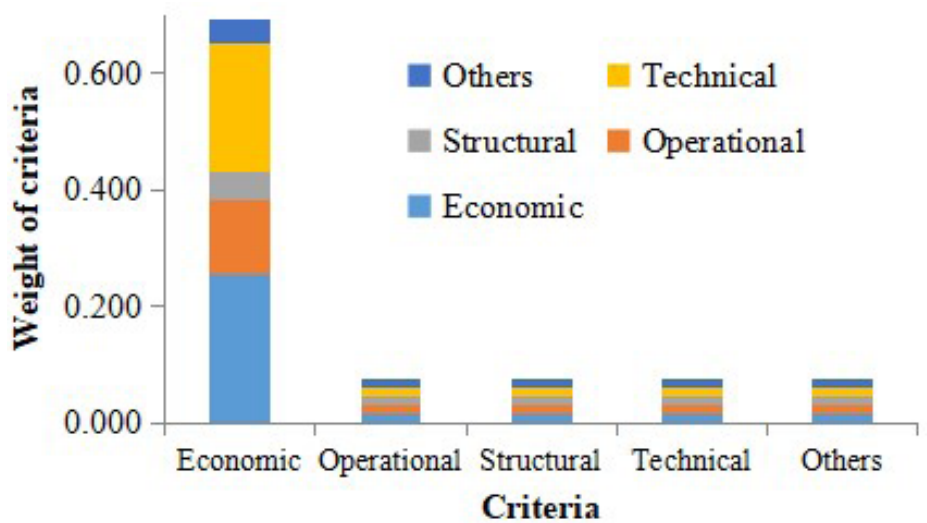

A

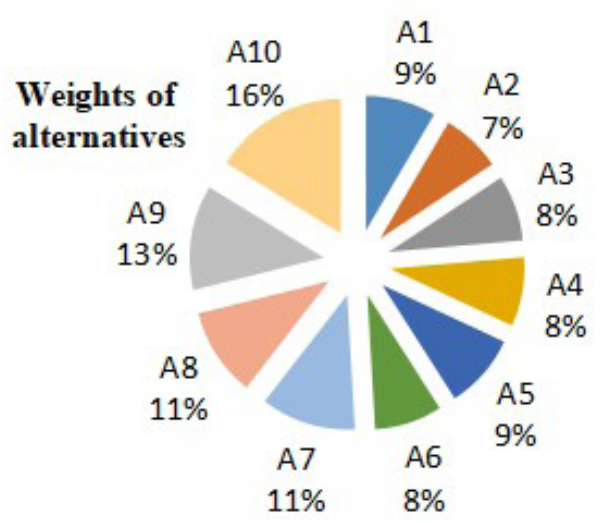

B

Figure 3. Priority analysis for microgrid $(A)$ weights of criteria and (B) scores obtained for alternatives if the economics criterion is assigned the highest (0.6923) and the rest having equal (each 0.0769) weights.

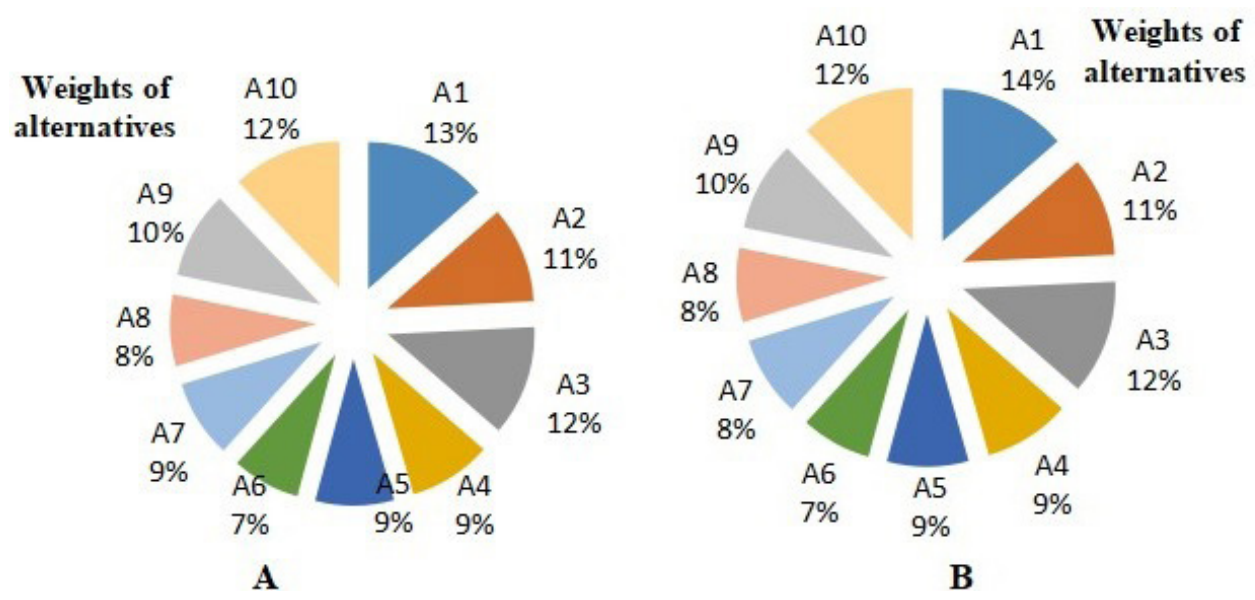

Figure 4. Weights of alternatives when (A) all five primary criteria have equal weight; and (B) based on experts scores.

The scenario when economic criteria are given the most importance is similar to the system simulated in HOMER Pro wherein other parameters like energy density, capacity utilization factor, modularity, footprint, performance degradation, appearance, autonomy, and others are often being overlooked. In this situation, the weights of each are shown in Figure 3A and all five sources (alternative A10) are part of the system and carries the highest priority followed by A9, A8, A7, A1, and so on as shown in Figure 3B. With various capacities of sources, an optimized case has been identified in the HOMER Pro software, which later has been used as base case for some of inputs for fuzzy-AHP-MCDM technique.

The CoE of $\$ 0.0694 / \mathrm{kWh}, \mathrm{NPC}$ of $\$ 327,230$, and the fairly attractive ROI of $76.6 \%$ are the base case results obtained from HOMER Pro.

Figures $4 \mathrm{~A}$ and $\mathrm{B}$ indicate the priorities as $\mathrm{A} 1, \mathrm{~A} 10, \mathrm{~A} 3, \mathrm{~A} 2, \mathrm{~A} 9$, and so on when all criteria are assigned equal weightage. The similar priorities, A1, A10, A3, A2, A9, and so on, are resulted even when the experts' scores are taken into computation. Here, it is assumed that the experts involved in scoring the primary criteria are relevant and have reasonable experience and expertise in their field. The result would deviate significantly from expected if experts have biased or prejudiced mindset. 


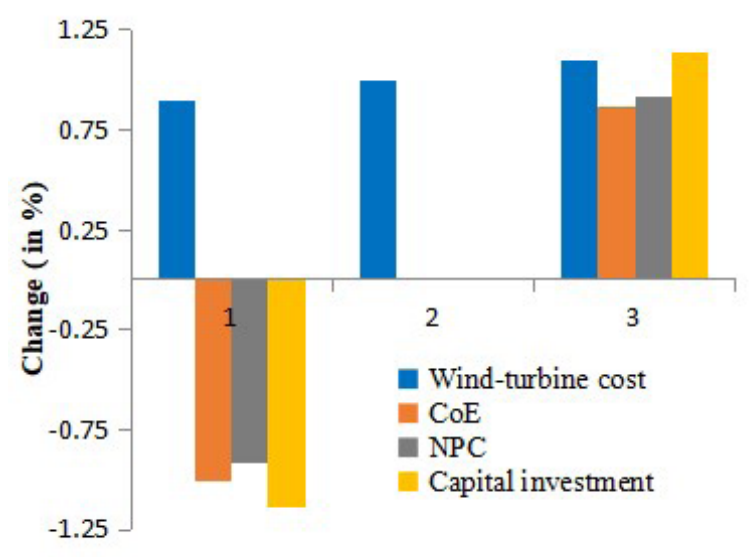

$\boldsymbol{A}$

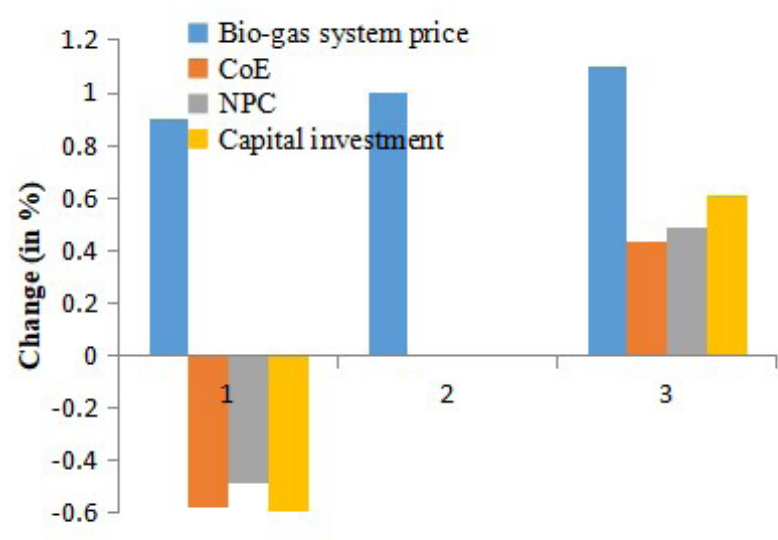

C

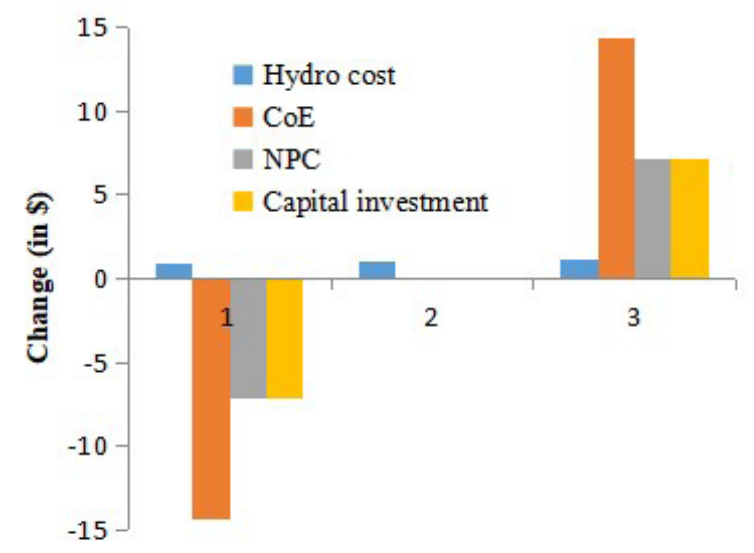

E

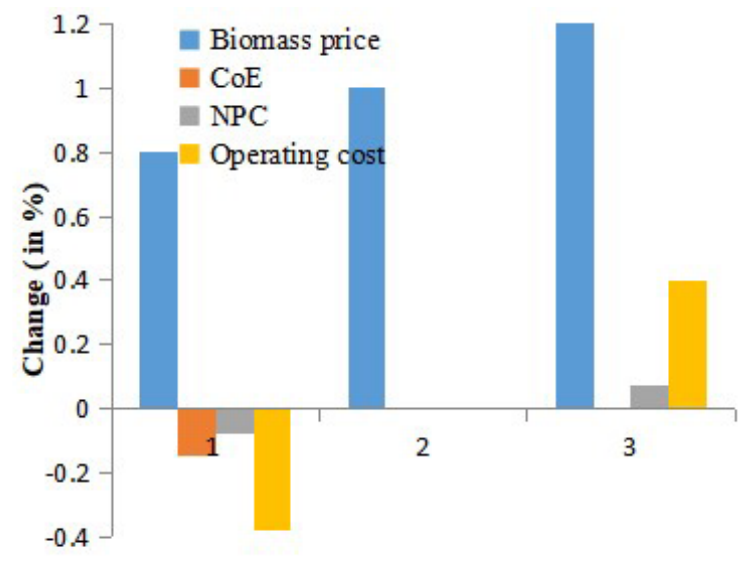

$B$

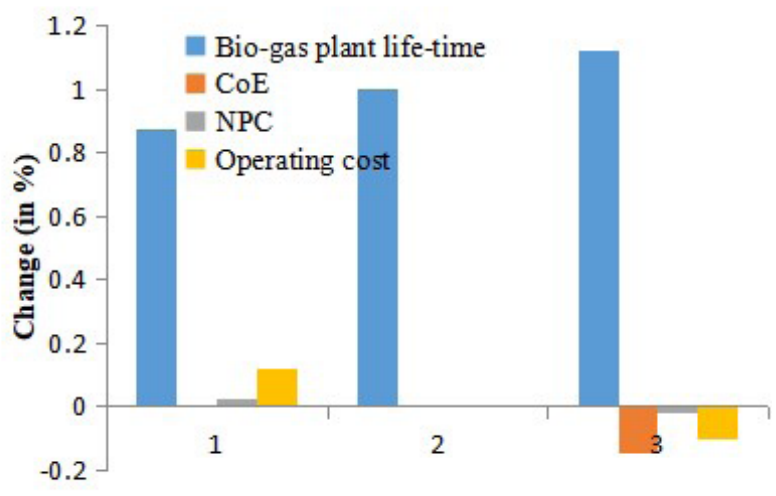

D

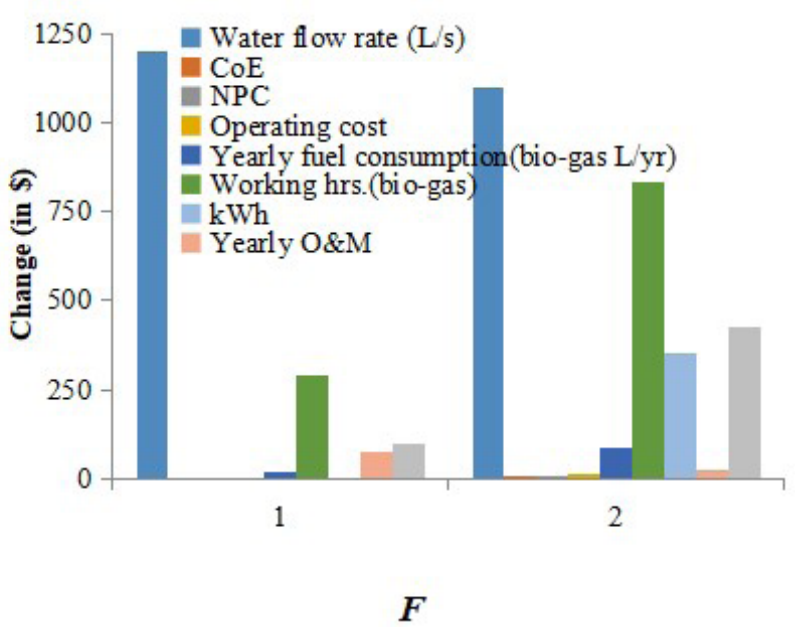

Figure 5. Sensitivity analysis for (A) wind-turbine price; (B) biomass price; (C) bio-gas genset system price; (D) bio-gas system life; (E) hydropower system cost; and (F) water flow rate for hydro-power.

The third part of study is the sensitivity analysis. The base case composition, which has been derived during the first part of simulation analysis done in HOMER Pro software and sensitivity analysis have been 
carried out with the following marginal variations in sensitivity parameters mentioned below. The results are shown in Figure 4:

1. Wind-turbine cost: $\pm 10 \%$

2. Biomass price (\$/tonne): $\pm 10 \%$

3. Bio-genset cost: $\pm 10 \%$

4. Bio-genset lifetime: $\pm 10 \%$

5. Flow rate for hydropower: $-10 \%$

6. Hydro plant cost: $\pm 10 \%$

If the price of wind-turbine deviates from the base one, then it has direct effect on CoE, NPC, and initial investment of project [Figure 5A]. Similarly, the CoE, NPC, and operating cost get affected by the fluctuation on the bio-mass price [Figure $5 \mathrm{~B}$ ]. The bio-mass system cost has same influence for windturbine cost [Figure 5C] and likewise bio-gas system plant life [Figure 5D]. Since the hydro-power plant incurs the highest capital investment, it will change CoE, NPC, and overall capital cost substantially compared to the others explained before [Figure 5E].

Finally, as the contribution of hydropower is more in terms of energy sharing, the change in water head/ level influences not only $\mathrm{CoE}$ and NPC but also fuel requirement/consumption and operating hours of the bio-gas plant as shown in Figure 5F.

The abscissa indicates three sensitivity options; 1 refers -10\%, 2 refers reference parameter and 3 indicates $+10 \%$ variations in parameters.

\section{CONCLUSIONS}

A methodology for designing and planning of isolated microgrid for a rural area of Tanzania was discussed in this paper. The population of the selected region was estimated to be 2500-3000 people consuming approximately $1000 \mathrm{kWh}$ of energy per day. The ranking of alternatives was decided using HOMER Pro and MCDM technique. In order to support the work, a detailed comparison between the result obtained from HOMER Pro software and fuzzy-AHP-MCDM technique was presented. The AHP-MCDM was treated to be sitting above the results generated by HOMER Pro. In this study, the subjective answers collected from experts in terms of scores were handled by fuzzy approach in preparing pair-wise comparison matrix of key criteria and quantitative or measurable criteria using AHP-MCDM technique. The parameters from optimal case obtained in HOMER Pro were used as reference for further analysis. From a sensitivity analysis, it was identified that the water head of a micro-hydro power plant is more impactful than the variation of other parameters. It affects not only CoE and NPC but also generated kWh and consumption of bio-gas significantly. It infers that from fuzzy-AHP-MCDM analysis, when only economic parameters are made emphatic, suppressing other criteria, it results in the use of all sources together. But contradictorily, when all are given equal importance and also when experts' scores are considered, in both cases it results into amalgamation of only two renewable sources, PV and wind energy-based generation. The result may vary significantly, as it depends strongly on the scores collected from experts which may otherwise will lead to unexpected outcome. Moreover, a sensitivity analysis was carried out to examine the impact of alternative selections on various significant indicators of the project. This analysis provided a framework to check feasibility for other such remote places or villages where electricity is unavailable or laying transmission lines is expensive, but rich in renewable energy source potential. Furthermore, the similar analysis could be extended with due modification for grid connected microgrid planning. 


\section{DECLARATIONS}

\section{Authors' contributions}

Made substantial contributions to conception and design of the study and performed data analysis and interpretation: Bohra SS, Anvari-Moghaddam A

Reviewed, corrected technical, and other details: Blaabjerg F, Mohammadi-Ivatloo B

\section{Availability of data and materials}

Not applicable.

\section{Financial support and sponsorship}

None.

\section{Conflicts of interest}

All authors declared that there are no conflicts of interest.

\section{Ethical approval and consent to participate}

Not applicable.

\section{Consent for publication}

Not applicable.

\section{Copyright}

(c) The Author(s) 2021.

\section{REFERENCES}

1. Ritchie H, Roser M. Energy. Available from: https://ourworldindata.org/energy [Last accessed on 22 Jun 2021]

2. Corfee-Morlot J(3Cs), Parks P, Ogunleye J, Ayeni F. Achieving clean energy access in sub-Saharan Africa. A case study for the OECD, UN Environment, World Bank project: Financing Climate Futures: Rethinking Infrastructure. Available from: https://www.oecd.org/ environment/cc/climate-futures/Achieving-clean-energy-access-Sub-Saharan-Africa.pdf [Last accessed on 22 Jun 2021]

3. Blimpo MP, Cosgrove-Davies M. Electricity access in Sub-Saharan Africa: uptake, reliability, and complementary factors for economic impact. Africa Development Forum. Washington, DC: World Bank; 2019. Available from: https://openknowledge.worldbank.org/ handle/10986/31333 [Last accessed on 22 Jun 2021]

4. World Energy Outlook. Report extract Electricity. Available from: https://www.iea.org/reports/world-energy-outlook-2018/electricity [Last accessed on 22 Jun 2021]

5. World Bank Group. Africa's pulse, No. 17, April 2018. Available from: https://openknowledge.worldbank.org/handle/10986/29667 [Last accessed on 22 Jun 2021]

6. Anvari-Moghaddam A, Mohammadi-ivatloo B, Asadi S, Larsen K, Shaidehpour M. Sustainable energy systems planning, integration, and management. Appl Sci 2019; 9:4451.

7. Najafi J, Peiravi A, Anvari-moghaddam A. Enhancing integrated power and water distribution networks seismic resilience leveraging microgrids. Sustainability 2020;12:2167.

8. Trotter PA, Mcmanus MC, Maconachie R. Electricity planning and implementation in sub-Saharan Africa: a systematic review. Renewable and Sustainable Energy Reviews 2017;74:1189-209.

9. Hartvigsson E, Ehnberg J, Ahlgren E, Molander S. Assessment of load profiles in minigrids: a case in Tanzania. Proceedings of 50th international Universities Power Engineering Conference (UPEC); 2015; Stoke on Trent, UK.

10. Bell K. Methods and tools for planning the future power system: issues and priorities. Available from: https://strathprints.strath. ac.uk/54341/1/Bell_IET_2015_Methods_and_tools_for_planning_the_future_power_system.pdf [Last accessed on 22 Jun 2021]

11. Bebic J. Power system planning: emerging practices suitable for evaluating the impact of high-penetration photovoltaics. National Renewable Energy Laboratory 2008.

12. Hirsch A, Parag Y, Guerrero J. Microgrids: a review of technologies, key drivers, and outstanding issues. Renewable and Sustainable Energy Reviews 2018;90:402-11.

13. Wang Y, Li F, Yu H, et al. Optimal operation of microgrid with multi-energy complementary based on moth flame optimization algorithm. Energy Sources, Part A: Recovery, Utilization, and Environmental Effects 2020;42:785-806.

14. Wu X, Shi S, Wang Z. Microgrid planning considering the supply adequacy of critical loads under the uncertain formation of submicrogrids. Sustainability 2019;11:4683. 
15. Mumtaz F, Bayram IS. Planning, operation, and protection of microgrids: an overview. Energy Procedia 2017;107:94-100.

16. Hafez O, Bhattacharya K. Optimal planning and design of a renewable energy based supply system for microgrids. Renewable Energy 2012;45:7-15.

17. Gamarra C, Guerrero JM. Computational optimization techniques applied to microgrids planning: a review. Renewable and Sustainable Energy Reviews 2015;48:413-24.

18. Navidi M, Tafreshi SMM, Anvari-moghaddam A. A game theoretical approach for sub-transmission and generation expansion planning utilizing multi-regional energy systems. International Journal of Electrical Power \& Energy Systems 2020;118:105758.

19. Kumar A, Sah B, Singh AR, et al. A review of multi criteria decision making (MCDM) towards sustainable renewable energy development. Renewable and Sustainable Energy Reviews 2017;69:596-609.

20. Kaya İ, Çolak M, Terzi F. Use of MCDM techniques for energy policy and decision-making problems: a review. Int J Energy Res 2018;42:2344-72.

21. Alizadeh R, Soltanisehat L, Lund PD, Zamanisabzi H. Improving renewable energy policy planning and decision-making through a hybrid MCDM method. Energy Policy 2020;137:111174.

22. He J, Yang X, Liu Y, Huang W, Chen J, Li D. Comprehensive Evaluation of Microgrid Planning Scheme based on AHP-Entropy method. 2019 IEEE Sustainable Power and Energy Conference (iSPEC); 2019; Beijing, China.

23. Bahramara S, Moghaddam MP, Haghifam M. Optimal planning of hybrid renewable energy systems using HOMER: a review. Renewable and Sustainable Energy Reviews 2016;62:609-20.

24. Jung J, Villaran M. Optimal planning and design of hybrid renewable energy systems for microgrids. Renewable and Sustainable Energy Reviews 2017;75:180-91.

25. Fulzele JB, Dutt S. Optimium planning of hybrid renewable energy system using HOMER. IJECE 2012;2:68-74.

26. Heleno M, Domenech BC, Cardoso G, Mashayekh S. The microgrid investment and planning in rural locations. Microgrids for rural areas: research and case studies. UK: The Institution of Engineering and Technology; 2020, p. 33-53.

27. Narayan A. A Framework for microgrid planning using multidisciplinary design optimization. Available from: http://hdl.handle. net/10012/9971 [Last accessed on 22 Jun 2021]

28. Jiménez-Estévez GA, Palma-Behnke R, Ortiz-Villalba D, Mata ON, Montes CS. It takes a village: social SCADA and approaches to community engagement in iolated microgrids. IEEE Power and Energy Mag 2014;12:60-9.

29. Vafaei M, Kazerani M. Optimal unit-sizing of a wind-hydrogen-diesel microgrid system for a remote community. 2011 IEEE Trondheim PowerTech; 2011, p. 1-7.

30. Logenthiran T, Srinivasan D, Khambadkone AM, Sundar Raj T. Optimal sizing of an islanded microgrid using evolutionary strategy. Proceedings of the 2010 IEEE 11th international conference on probabilistic methods applied to power systems; 2010, p. 12-9.

31. Erdinc O, Uzunoglu M. Optimum design of hybrid renewable energy systems: overview of different approaches. Renewable and Sustainable Energy Reviews 2012;16:1412-25.

32. Chen SX, Gooi HB, Wang MQ. Sizing of Energy Storage for Microgrids. IEEE Trans Smart Grid 2012;3:142-51.

33. Fan Y, Rimali V, Tang M, Nayar C. Design and implementation of stand-alone smart grid employing renewable energy resources on Pulau Ubin Island of Singapore. 2012 Asia-Pacific symposium on electromagnetic compatibility; 2012, p. 441-5.

34. Kumaravel S, Ashok S, Balamurugan P, Techno-economic feasibility study of biomass based hybrid renewable energy system for microgrid application. Proceedings of the 2012 international conference on green technology; 2012, p. 107-16.

35. U.S. Agency for International Development. Tanzania power Africa fact sheet. Available from: https://www.usaid.gov/powerafrica/ tanzania [Last accessed on 22 Jun 2021]

36. The World Bank. Increasing electricity access in Tanzania to reduce poverty. Available from: https://www.worldbank.org/en/ results/2016/12/06/increasing-electricity-access-in-tanzania-to-reduce-poverty [Last accessed on 22 Jun 2021]

37. Scarlat N, Dallemand J, Fahl F. Biogas: Developments and perspectives in Europe. Renewable Energy 2018;129:457-72.

38. FurtherAfrica. Tanzania has potential to build 700,000 biogas digesters. Available from: https://furtherafrica.com/2018/01/08/tanzaniahas-potential-to-build-700000-biogas-digesters/ [Last accessed on 22 Jun 2021]

39. HOMER Energy. Available from: https://www.homerenergy.com [Last accessed on 22 Jun 2021]

40. PV Module Product Datasheet MaxPower CS6X-P. Available from: https://www.renewenergy.com.au/wp-content/uploads/Datasheet_ CS6X-P_au.pdf [Last accessed on 22 Jun 2021]

41. GILDEMEISTER energy solutions. CellCube. The storage system for intelligent power supply. Available from: https://vsunenergy.com. au/wp-content/uploads/2016/11/CellCube-Brochure.pdf [Last accessed on 22 Jun 2021]

42. Australian Wind and Solar. AWS HC wind turbines. Available from: https://www.australianwindandsolar.com/aws-hc-wind-turbines [Last accessed on 22 Jun 2021]

43. Natel energy. FREE JET hydroEngine ${ }^{\circledR}$. Available from: http://www.natelenergy.com/wp-content/uploads/2016/07/Natel_FREE_JET_ hydroEngine_jul2016.pdf [Last accessed on 22 Jun 2021]

44. Akinyele D. Analysis of photovoltaic mini-grid systems for remote locations: a techno-economic approach. Int J Energy Res 2018;42:1363-80.

45. National Renewable Energy Lab database. Solar resource data and tools. Available from: https://www.nrel.gov/grid/solar-resource/ renewable-resource-data.html [Last accessed on 22 Jun 2021]

46. NASA. NASA prediction of worldwide energy resources. Available from: https://power.larc.nasa.gov [Last accessed on 22 Jun 2021$]$

47. Algarín CR, Llanos AP, Castro AO. An Analytic Hierarchy Process Based Approach for Evaluating Renewable Energy Sources. International Journal of Energy Economics and Policy 2017;7:38-47. 
48. Bohra SS, Anvari-Moghaddam A, Mohammadi-Ivatloo B. AHP-Assisted Multi-Criteria Decision-MakingModel for Planning of Microgrids. Procedding of 45th Annual Conference of the IEEE Industrial Electronics Society; 2019; Portugal, Lisbon.

49. Cheng C. Group opinion aggregationbased on a grading process: a method for constructing triangular fuzzy numbers. Computers \& Mathematics with Applications 2004;48:1619-32.

50. Saaty TL. A scaling method for priorities in hierarchical structures. J Math Psychol 1977;15:234-81.

51. Alonso JA, Lamata MT. Consistency in the analytic hierarchy process: a new approach. Int J Unc Fuzz Knowl Based Syst 2011;14:44559. 